\title{
INFLUENCE OF AUSTENITE GRAIN SIZE ON THE OVERAGING TREATMENT OF CONTINUOUS ANNEALED DUAL PHASE STEELS
}

\author{
A. García-Junceda ${ }^{1}$, F.G. Caballero ${ }^{1}$, T. Iung $^{2}$, C. Capdevila ${ }^{1}$, C. García de \\ Andrés ${ }^{1}$
}

${ }^{1}$ Solid-Solid Phase Transformations Group (MATERALIA), Department of Physical Metallurgy, Centro Nacional de Investigaciones Metalúrgicas (CENIM), Consejo Superior de Investigaciones Científicas (CSIC), Avda. Gregorio del Amo, 8, 28040 Madrid, Spain, www.cenim.csic.es

${ }^{2}$ Arcelor Research, Voie Romaine B.P. 320, 57214 Maizières-Lès-Metz, France

Keywords: Dual-phase steel; Continuous annealing; Austenite grain size; Overaging.

\begin{abstract}
A dual-phase steel with an initial coarse microstructure was refined, by means of a thermal treatment, to study the influence of the austenite grain size reached during an intercritical annealing treatment on the martensite start temperature. Thus, the effect of the austenite grain size on a subsequent overaging treatment was also investigated. It was found that a coarser austenite grain size leads to a higher martensite start temperature and a lower amount of non-tempered martensite and/or austenite (MA constituents) volume fraction after a continuous annealing and overaging treatment. The non-tempered martensite and/or austenite volume fraction always was higher for the highest overaging temperature.
\end{abstract}

\section{INTRODUCTION}

The demand for weight reduction in the automotive industry has converted dual-phase (DP) steels into a commercial material for automotive application, due to their exceptional combination of high tensile strength, low yield strength, high initial work hardening rate, continuous yielding, good ductility and drawability. The dual phase microstructure consists of a fine dispersion of martensite (10 to $40 \mathrm{vol} . \%)$ in a soft pure ferrite matrix, with the possible presence of some retained austenite and bainite. Dual phase steels are conventionally produced by intercritical annealing of low carbon steels, consisting on the partial austenitisation in the intercritical region followed by rapid cooling to transform the austenite into martensite. Recent studies attempt to explain the reason for mechanical failure of traditional dual phase steels ${ }^{1-5}$. It seems that the origin of this problem is the significant difference in hardness that exhibits the ferrite and martensite phases in the microstructure. An interesting alternative microstructure might be that consisting of ferrite, tempered martensite and MA constituents, as reviewed by Honeycombe and Bhadeshia ${ }^{6}$. Thus, during an overaging treatment after rapid cooling and before reaching room temperature, martensite, which is a supersaturated solid solution of carbon in iron, rejects carbon in form of fine carbides and lowers its hardness, so the difference in hardness along the matrix is not significant. In this sense, it is necessary to perform an overaging treatment after the intercritical annealing that leads to a final microstructure in which, apart from ferrite and tempered martensite, there are some MA constituents with a martensite start 
temperature, $M_{\mathrm{s}}$, below the overaging temperature that are formed in the subsequent quenching.

The influence of the chemical composition of the steel on the values of $M_{\mathrm{s}}$ has been extensively reported ${ }^{7-12}$. In all these studies the carbon seems to be the alloying element that affects more strongly the values of $M_{\mathrm{s}}$. However, the effect of the austenite grain size, $A G S$, reached after partial austenitisation in the intercritical annealing, on the $M_{\mathrm{s}}$ is still not completely understood. Some authors explain the role of the austenite grain size on the martensite start temperature in a theoretical way concluding that the reduction of the grain size increases the resistance of the austenite to plastic deformation locally and macroscopically ${ }^{13,14}$. The decrease of the austenite grain size impedes the martensite transformation by increasing the non-chemical free energy opposing the transformation, so the value of the $M_{\mathrm{s}}$ is expected to decrease ${ }^{13}$.

Therefore, both the $A G S$ and the $M_{\mathrm{s}}$ are linked and the $A G S$ is an important parameter to be considered in the selection of an adequate overaging treatment in the processing route of dual phase steels. Thus, the purpose of the present work is to analyse the influence of the $A G S$ on the martensite transformation of austenite partially formed during intercritical annealing, and therefore on the overaging of continuously annealed dual phase steels. In order to obtain different austenite grain sizes after partial austenitisation, two initial microstructures, one coarser than the other, were chosen.

\section{EXPERIMENTAL PROCEDURE}

The chemical composition of the studied dual phase steel is, in wt- $\%, 0.2 \mathrm{C}, 1.65 \mathrm{Mn}$, $1.65 \mathrm{Si}, 0.02 \mathrm{Cr}, 0.015 \mathrm{P}$ and $0.038 \mathrm{Al}$. This steel was elaborated by Arcelor using a $60 \mathrm{~kg}$ vacuum induction furnace under inert atmosphere. Semi rolled slabs of $35 \mathrm{~mm}$ thickness were heated up to $1300^{\circ} \mathrm{C}$ during $24 \mathrm{~h}$ for the homogenisation treatment that conducted to a coarse initial microstructure.

To refine the initial microstructure of the as-received steel by means of a thermal treatment, specimens were austenitised at $900^{\circ} \mathrm{C}$ during $60 \mathrm{~s}$ at a heating rate of $5^{\circ} \mathrm{C} / \mathrm{s}$ and subsequently gas cooled to room temperature at a constant rate of $5^{\circ} \mathrm{C} / \mathrm{s}$. The programmable heating-holding-cooling devices of a high-resolution dilatometer were used to perform all the treatments. For this purpose, cylindrical solid specimens of $2 \mathrm{~mm}$ in diameter and $12 \mathrm{~mm}$ in length were used. For generating the dilatometric curves and to measure the values of $M_{\mathrm{s}}$ and martensite finish temperature, $M_{\mathrm{f}}$, each sample was held in the dilatometer between two silica rods, with one of the rods fixed, and the other connected to a linear voltage differential transducer, LVDT. A reference rod was also connected to the LVDT, the other end was connected with a fixed plate. Thus, the relative displacement between the rod touching the sample and the reference rod was measured. The samples were heated by an induction coil and the temperature was measured by a Pt-Pt10\%Rh (type S) thermocouple centrally spot welded on their surface. Heating was carried out under a vacuum of $10^{-5} \mathrm{mbar}$. Samples were gas cooled using helium. The excellent efficiency of heat transmission and the very low thermal inertia of the system ensure cooling rates up to $500^{\circ} \mathrm{C} / \mathrm{s}$. The values of $M_{\mathrm{s}}$ and $M_{\mathrm{f}}$ were determined using dilatometric data obtained from the experimental curves registered during quenching where the variation of the relative length changes as a function of temperature $\left(\Delta \mathrm{L} / \mathrm{L}_{0}=\mathrm{f}(\mathrm{T})\right)$ is represented ${ }^{15}$. Results correspond to the average of the $M_{\mathrm{s}}$ and $M_{\mathrm{f}}$ values measured in five dilatometric curves with the respective experimental scatter. 
Both the coarse and the refined microstructures were intercritically annealed heating at a rate of $5^{\circ} \mathrm{C} / \mathrm{s}$ to $750^{\circ} \mathrm{C}$ during 6 minutes (time long enough to ensure a steady state in terms of austenite fraction) before gas quenching to room temperature, to obtain two dual-phase microstructures, coarse and fine, with approximately the same volume fractions of ferrite and martensite.

Eventually, to study the effect of the $A G S$ on the overaging microstructures, samples were continuous annealed at $750^{\circ} \mathrm{C}$ during 6 minutes and air cooled to the intermediate overaging temperature of $180^{\circ} \mathrm{C}$ or $200^{\circ} \mathrm{C}$ during 90 minutes, before gas quenching to room temperature (Fig. 1).

Specimens for light and scanning electron microscopy were ground and polished using standard techniques for metallographic examination. A 3\% nital etching solution was used for the characterisation of the microstructure at low magnification. To reveal more in detail the microstructure formed by tempered martensite and MA constituents, samples were observed by scanning electron microscopy (SEM) in a Jeol 6400 microscope after the continuous annealing and overaging treatment. The volume fractions of ferrite, $V_{\alpha}$, and martensite (austenite before quenching), $V_{\mathrm{M}}$, obtained after the intercritical annealing treatment and the volume fractions of tempered martensite, MA constituents and ferrite present in the microstructure after the continuous annealing and overaging treatment, were obtained by a systematic manual point counting procedure on electronic micrographs ${ }^{16}$. The ferrite and austenite grain sizes were determined on optical micrographs (magnification 1000x) with the help of a digital image processing program and results were analysed in terms of mean values of the equivalent circle diameter with an accuracy of $0.5 \mu \mathrm{m}$.

\section{RESULTS AND DISCUSSION}

\section{As-received microstructure, refinement and intercritical annealing}

The as-received material consists on a coarse microstructure formed by ferrite (70 vol.\%) and pearlite (30 vol.\%) with an average ferrite grain size of $25 \mu \mathrm{m}$ (Fig. 2.a.). The material presents some iron oxides that reveal internal oxidation problems during the homogenisation treatment. No bands were found, which indicates a homogeneous distribution in $\mathrm{Mn}$. The first aim of the present work was to refine the initial microstructure in order to get two different values of $A G S$ after partial austenitisation in the intercritical annealing of both coarse and fine microstructures. The resulting refined microstructure is shown in Fig. 2. b. This microstructure is mainly formed by ferrite (72 vol.\%), with some randomly dispersed martensite (16 vol.\%) and pearlite (12 vol.\%). Although some martensite is present and the quantity of pearlite is smaller in this microstructure than in the as-received microstructure, it is expected that these differences will not affect significantly the kinetics of the austenite formation during the intercritical annealing ${ }^{17}$. As it was intended, the resulting grain size has decreased compared with the original sample, since the average ferrite grain size in this case was measured to be $5 \mu \mathrm{m}$.

Fig. 3 shows the microstructure of both coarse and fine samples after intercritical annealing. Both microstructures are formed by approximately $65 \%$ of ferrite, and $35 \%$ of martensite, (see Table 1). It is clear from these experimental results that the kinetics of partial austenitisation was quite similar for both initial microstructures, and that they contain nearly the volume fractions desired. 
Surprisingly, in the case of the coarse microstructure a Widmanstätten type of austenite microstructure was found, in austenite growing along ferrite grain boundaries (Fig. 3.a.). This Widmanstätten type of austenite is a unique morphology, which has been rarely reported in the literature ${ }^{18-20}$. Jeong Yi et al. observed this growth of austenite when they studied the intercritical annealing of a dual phase steel with a ferrite-pearlite initial microstructure, thus they suggested that when the ferrite grain boundaries are site-saturated with austenite particles, the austenite particles can grow to the Widmanstätten side plates which are more effective to rapidly increase the austenite volume fraction than the normal growth mode of planar interface displacement. The austenite cusps shown in Fig. 3.a. collect the carbon atoms necessary for growth more effectively than planar interfaces, hence Widmanstätten type of austenitic growth is faster than planar and this microstructure is preferred. In the refined microstructure, this type of Widmanstätten morphology was not observed during the isothermal holding (Fig. 3.b.). Since the grains are smaller in this microstructure, the interface area of ferrite/austenite is larger. If this interface suffers a displacement, the austenite volume fraction will change considerably. The austenite can grow to Widmanstätten morphology when the density of the ferrite/austenite interface is low and the carbon diffusion from carbon sources to the austenite fronts is limited by some reasons ${ }^{20}$. Concerning the grain size distribution of the austenite phase partially formed during intercritical annealing, shown in Fig. 4, it was observed that the average grain size in the coarse microstructure is about five times bigger than in the fine microstructure. As expected, the coarse initial microstructure has led to a dual phase microstructure with coarser martensite islands (former austenite) than the finer one.

$M_{\mathrm{s}}$ temperatures (see Table 2) of austenite partially formed during intercritical annealing suggest that the increase in the austenite grain size raises the $M_{\mathrm{s}}$ for identical austenite volume fraction. The $M_{\mathrm{f}}$ temperatures shown in Table 2 were similar for both coarse and fine microstructures. The fact of reaching the same austenite volume fraction on equilibrium conditions during partial austenitisation in the intercritical annealing of both coarse and fine microstructures, allows the assumption that the average content in alloying elements in the total austenite volume is equal in both microstructures. Thus, a different compositional average content in alloying elements in the whole austenite volume does not explain the experimental differences observed in the values of the $M_{\mathrm{s}}$ temperatures. Therefore, the measured values of $M_{\mathrm{s}}$ can only be explained in terms of the differences on $A G S$ reached on both coarse and fine initial microstructures after partial austenitisation during intercritical annealing. Hence, it can be concluded that the values of $M_{\mathrm{s}}$ for a given steel increase with the increase of the austenite grain size.

\section{Overaging}

Two different overaging temperatures, 180 and $200{ }^{\circ} \mathrm{C}$, were chosen to study the influence of the austenite grain size obtained after partial austenitisation on the formation of tempered martensite and MA constituents during an overaging treatment and subsequent quenching. Both overaging temperatures were in the range of temperatures $M_{\mathrm{s}}-M_{\mathrm{f}}$ determined for the coarse and fine microstructures (see Table 2). Final microstructures for both overaging temperatures consist on tempered martensite, some MA phases and ferrite, as shown in the scanning electron micrographs of Fig. 5 for both coarse and fine initial microstructures. The volume fractions of tempered martensite, MA constituents and ferrite obtained after the overaging treatments for each initial microstructure are shown in Fig. 6. Continuous annealing and subsequent overaging treatment of fine initial microstructures lead to higher volume fraction of MA 
constituents than that of coarse initial microstructures, given an overaging temperature. This can be explained by the formation of a higher quantity of small austenite islands highly enriched in carbon during partial austenitisation in the refined microstructure. In initial microstructures composed basically by ferrite and pearlite, as is the present case, the nucleation of austenite occurs primarily at the edges of the pearlite colonies and the growth of austenite nuclei is controlled by the rate of carbon diffusion ${ }^{19,21}$. When the dissolution of pearlite is completed, subsequent growth of this carbon enriched austenite into ferrite to achieve partial equilibrium takes place. Since the fine microstructure has small and randomly scattered pearlitic colonies, after the intercritical annealing treatment they will generate small austenite islands with large carbon contents. These austenite islands will be stable at the overaging temperature because of their high carbon content, so they do not transform to martensite during the cooling to the overaging treatment, producing MA constituents after quenching to room temperature.

On the other hand, coarse microstructures have very large pearlitic colonies. These colonies will transform to coarser austenite islands. Since the transformation grade of a coarse austenite island is higher than in a smaller one, its carbon content will be lower and more homogeneous. Therefore, a higher martensite volume fraction will be formed during rapid cooling to overaging temperature and a higher volume fraction of tempered martensite will be present on the final coarse microstructure, as was observed above. Eventually, this work suggests that the increase in the overaging temperature raises the volume fraction of MA constituents presents in the final microstructure. This is not surprising, since at an overaging temperature of $200^{\circ} \mathrm{C}$ there are some austenite regions that did not transform to martensite during rapid cooling to overaging temperature because their values of $M_{\mathrm{s}}$ were below this temperature. However, at $180^{\circ} \mathrm{C}$ some of these austenite regions have a local carbon content that leads to $M_{\mathrm{s}}$ values between $200^{\circ} \mathrm{C}$ and $180^{\circ} \mathrm{C}$, so they transform to martensite in the cooling subsequent to the intercritical annealing treatment and they are tempered during the overaging, reducing the final amount of MA constituents.

\section{CONCLUSIONS}

The present investigation successfully managed to study the influence of the austenite grain size on the martensite start temperature of austenite partially transformed during intercritical annealing in a dual phase steel. It was concluded that the martensite start temperature increases with the austenite grain size reached during intercritical austenitisation.

Moreover, it has been found that an increase in the quantity of small carbon-enriched austenite islands, obtained during partial austenitisation of a fine microstructure, leads to higher volume fractions of MA constituents after continuous annealing and subsequent overaging treatment.

Finally, it was observed that the increase in the overaging temperature raises the volume fraction of MA phases present in the final microstructure of continuous annealed and overaged dual-phase steels.

\section{ACKNOWLEDGEMENTS}


The authors express their gratitude for the financial support from the European Coal and Steel Community (ECSC-7210-PR-349). A. García-Junceda would like to express her gratitude for the financial support in the form of a $\mathrm{PhD}$ research contract (FPU program) from the Spanish Ministerio de Educación y Ciencia. The authors are extremely grateful to Audrey Couturier from Arcelor Research (Metz, France) for her support in this experimental work.

\section{REFERENCES}

${ }^{1}$ B. Grushko and B. Z. Weiss: Scr. Metall., 1989, 23, 865-870.

${ }^{2}$ H.G. Read: Scr. Mater., 1997, 37, N.2, 151-157.

${ }^{3}$ S.S.M. Tavares, P.D. Pedroza, J.R. Teodósio and T. Gurova: Scr. Mater., 1999, 40, N.8, 887-892.

${ }^{4}$ X. Fang, Z. Fan, B. Ralph, P. Evans and R. Underhill: J. Mater. Process. Tech., 2003, 132, 215-218.

${ }^{5}$ A. Joarder, J.N. Jha, S.N. Ojha and S. Sarma: Mater. Charact., 1990, 25, 199-209.

${ }^{6}$ R.W.K. Honeycombe and H.K.D.H. Bhadeshia: 'Steels Microstructure and Properties', 171; 1995, London, Edward Arnold.

${ }^{7}$ K.W. Andrews: J. Iron Steel Inst., 1965, 203, 721-727.

${ }^{8}$ A.B. Greninger and A.R. Troiano: Trans. Am. Soc. Met., 1944, 33, 537-574.

${ }^{9}$ P. Payson and C.H. Savage: Trans. Am. Soc. Met., 1944, 33, 261-280.

${ }^{10}$ L. A. Carapella: Metal. Prog., 1944, 46, N.1, 108-118.

${ }^{11}$ R.A. Grange and H.M. Stewart: Trans. AIME., 1946, 167, 467-490.

${ }^{12}$ W. Steven and A.G. Haynes: J. Iron Steel Inst., 1956, 183, 349-359.

${ }^{13}$ P.J. Brofman and G.S. Ansell: Metall. Trans. A, 1983, 14A, 1929-1931.

${ }^{14}$ C. Capdevila, F.G. Caballero and C. García de Andrés: Mater. Sci. Technol., 2003, 19, 581-586.

${ }^{15}$ C. García de Andrés, F.G. Caballero, C. Capdevila and L.F. Álvarez: Mater. Charact., 2002, 48, 101-111.

${ }^{16}$ E.E. Underwood: 'Quantitative Stereology', 73-75; 1970, Addison-Wesley Publishing Co., Reading, MA.

${ }^{17}$ F. G. Caballero, A. García-Junceda, C.Capdevila and Carlos García de Andrés: Mater. Trans., 2006, 47, N.9, 2269-2276.

${ }^{18}$ K. J. Albutt and S. Garber: J. Iron Steel Inst., 1966, 204, 1217-1222.

${ }^{19}$ G.R. Speich, V.A. Demarest and R.L. Miller: Metall. Trans. A, 1981, 12A, 1419-1428.

${ }^{20}$ Joon Jeong Yi, In Sup Kim and Hyung Sup Choi: Metall. Trans. A, 1982, 16A, $1237-$ 1245.

${ }^{21}$ A. Roósz, Z. Gácsi and E.G. Fuchs: Acta Metall., 1983, 31, 509-517.

\section{LIST OF FIGURE CAPTIONS}

Fig. 1. Scheme of continuous annealing and overaging treatment.

Fig. 2. Optical micrographs of: a) as-received microstructure, b) microstructure after refinement. $\alpha$-Ferrite, P- Pearlite, M-Martensite. Nital etching.

Fig. 3. Optical micrographs of microstructures obtained after intercritical annealing: a) coarse, b) fine microstructure. $\gamma_{w}-$ Widmanstätten type of austenite. Nital etching.

Fig. 4. Distribution of $A G S$ after partial austenitisation in the intercritical annealing. DAverage austenite grain diameter. 
Fig. 5. Scanning electron micrographs after continuous annealing and: a) overaging at $180^{\circ} \mathrm{C}$, coarse microstructure, b) overaging at $180^{\circ} \mathrm{C}$, fine microstructure, c) overaging at $200^{\circ} \mathrm{C}$, coarse microstructure, d) overaging at $200^{\circ} \mathrm{C}$, fine microstructure. T-

Tempered martensite, MA- Martensite and/or austenite constituents. Nital etching. Fig. 6. Volume fractions of tempered martensite, MA constituents and ferrite in continuous annealed and overaged samples. CM-Coarse microstructure, FN- Fine microstructure.

\section{TABLES}

Table 1. Ferrite and martensite volume fraction after intercritical annealing in both coarse and fine microstructures.

\begin{tabular}{ccc}
\hline Initial microstructure & $V_{\alpha}(\%)$ & $V_{\mathrm{M}}(\%)$ \\
\hline Coarse & $64 \pm 4$ & $36 \pm 4$ \\
\hline Fine & $65 \pm 3$ & $35 \pm 3$
\end{tabular}

Table 2. $M_{\mathrm{s}}$ and $M_{\mathrm{f}}$ temperatures of austenite partially formed during intercritical annealing.

\begin{tabular}{ccc}
\hline Microstructure & $M_{\mathrm{s}}\left({ }^{\circ} \mathrm{C}\right)$ & $M_{\mathrm{f}}\left({ }^{\circ} \mathrm{C}\right)$ \\
\hline Coarse & $256 \pm 10$ & $148 \pm 8$ \\
\hline Fine & $224 \pm 6$ & $152 \pm 6$ \\
\hline
\end{tabular}



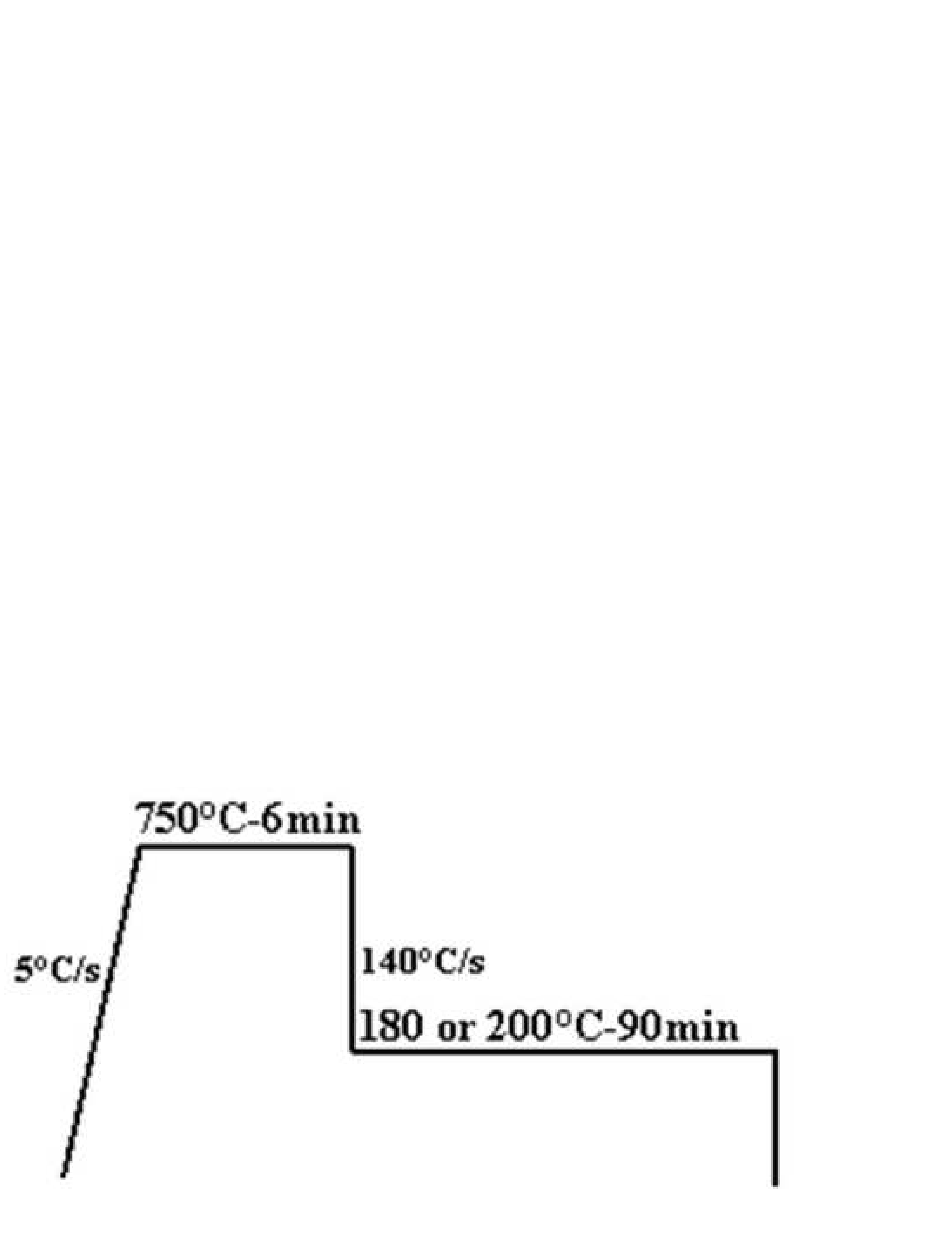

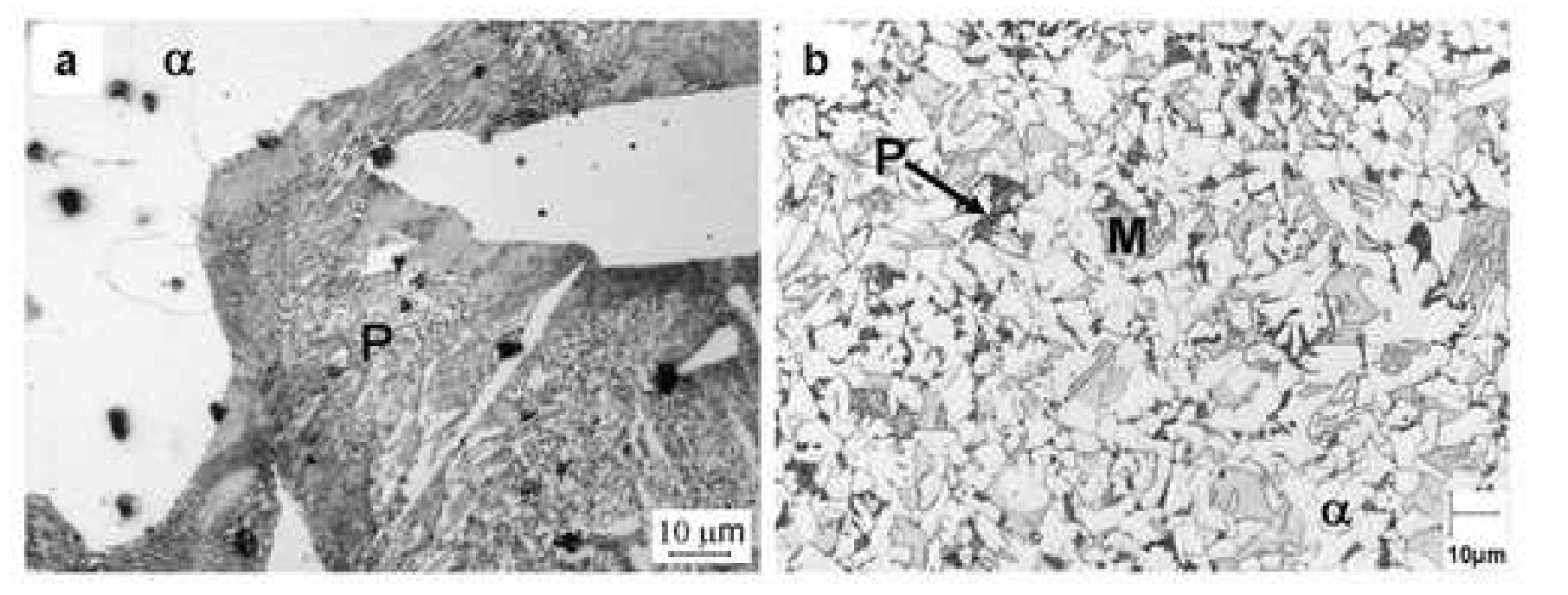

Figure $\square$

]

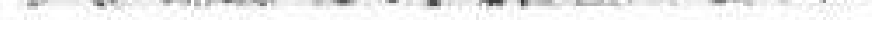

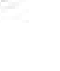



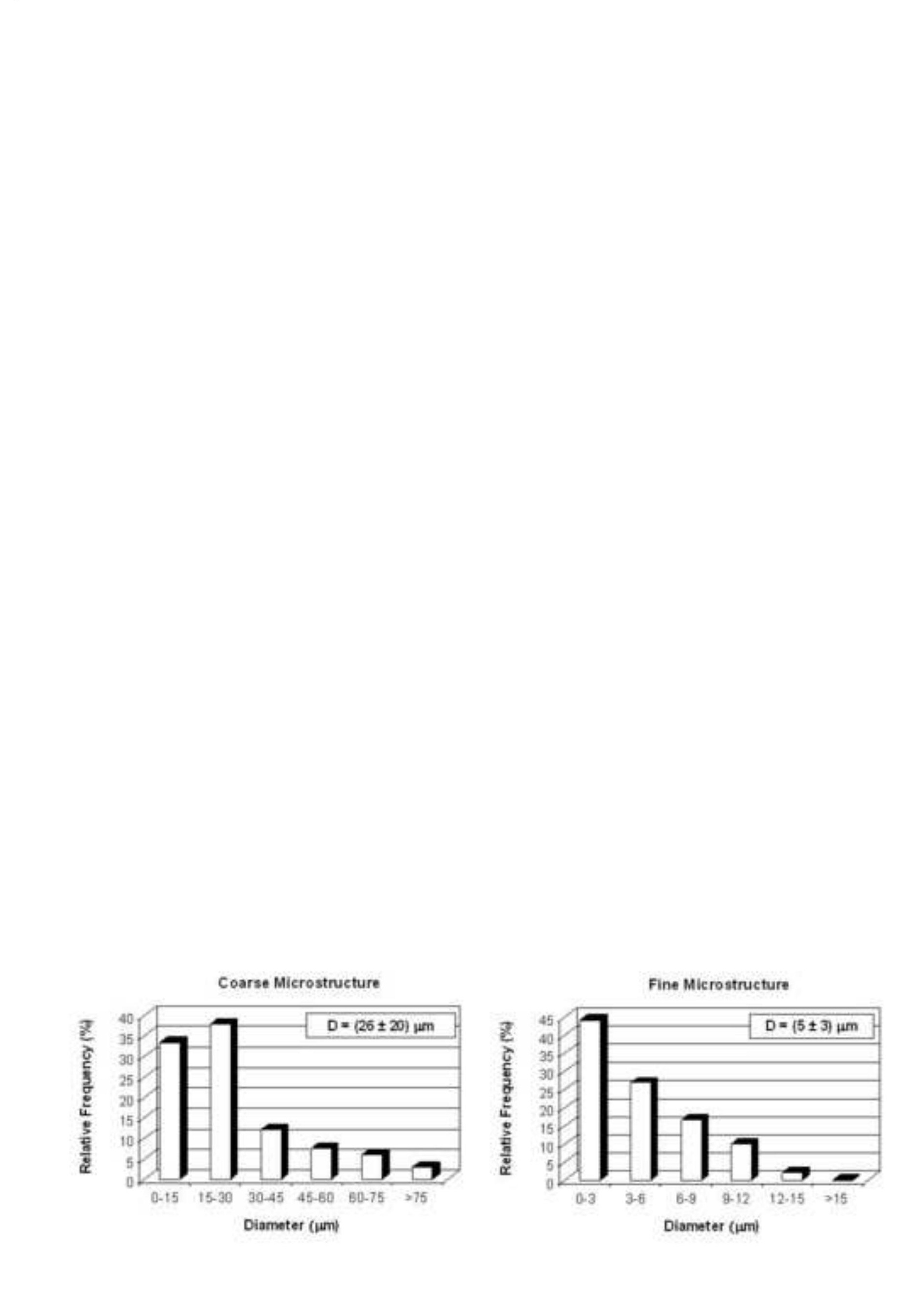

Figure $\square$

10

gure

Fine Microstructure
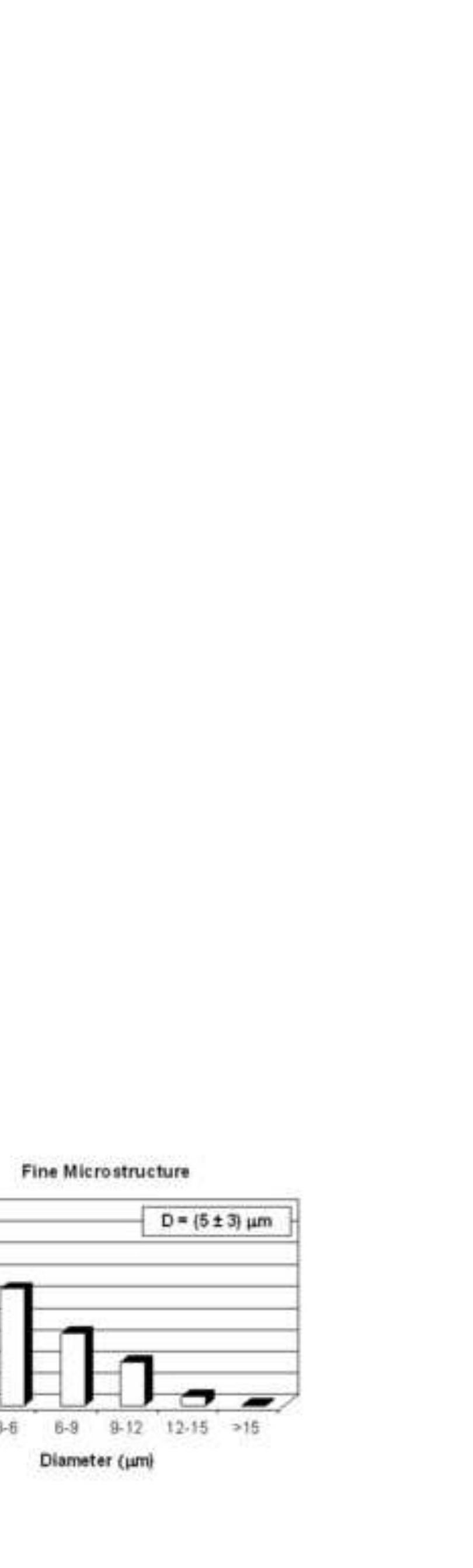

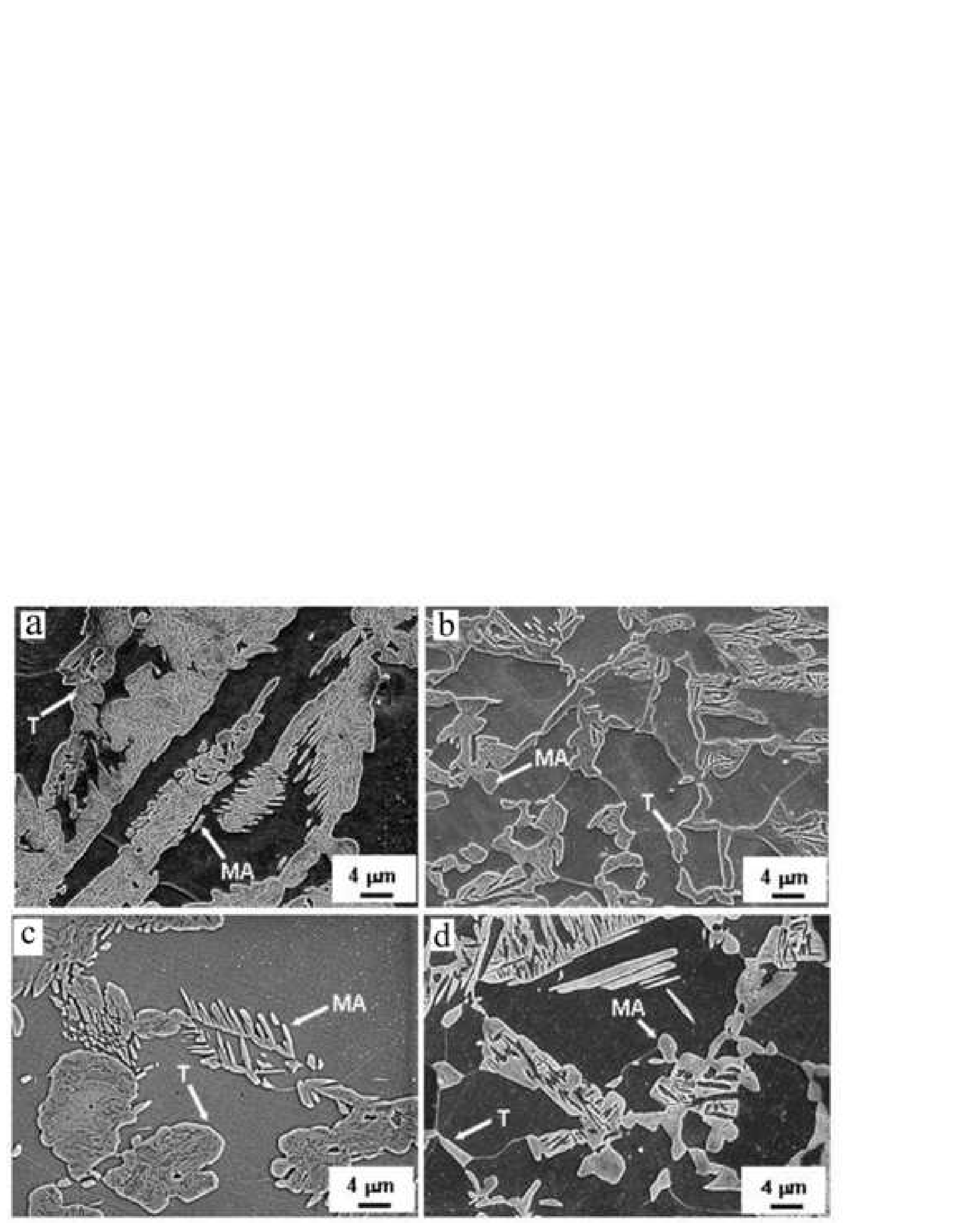


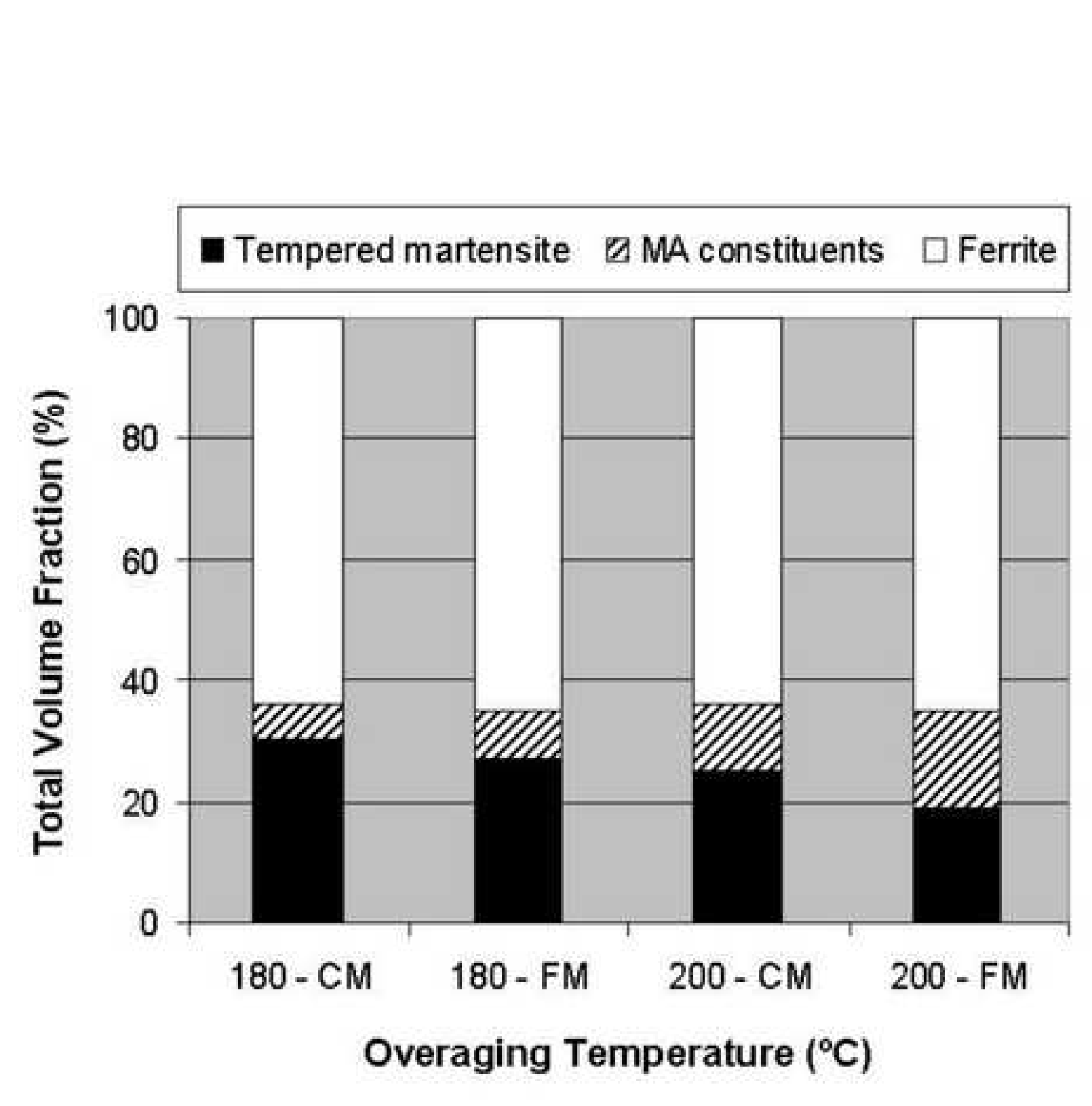

(⿸丆口

]
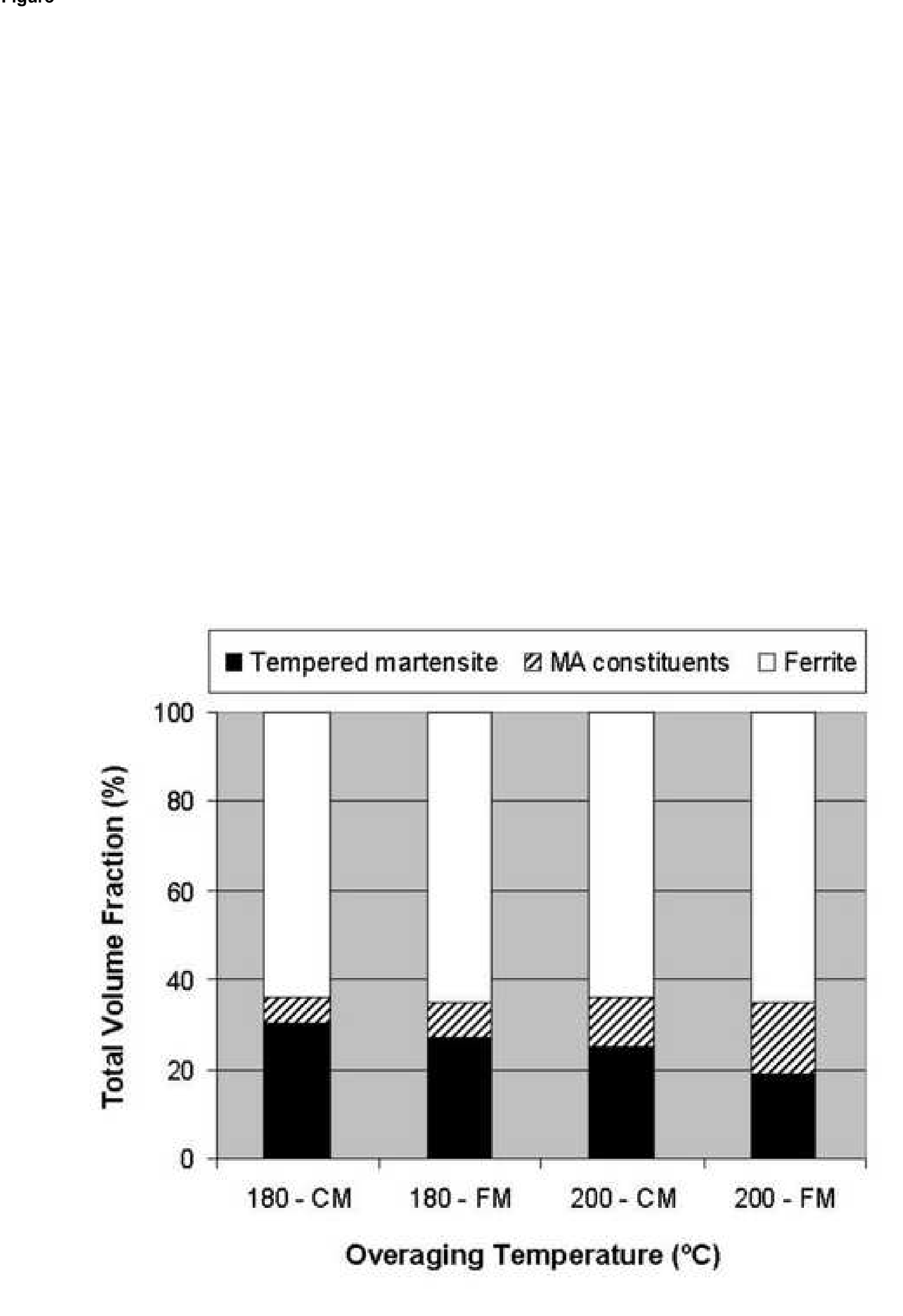
Figure 4: The number of bins has been chosen considering the error bar in the average austenite grain size diameter, that is $20 \mu \mathrm{m}$ in the coarse microstructure and $3 \mu \mathrm{m}$ in the fine microstructure.

Table 2: Martensite finish temperature values, Mf, have been included in Table 2 as Referees suggested. In this sense, we have decided to keep this Table in the manuscript.

Page 4: The paper of Kaluba et al. explains the formation of Widmanstätten-shaped austenite in a bainitic initial microstructure as the result of a superheating (between 200$2000^{\circ} \mathrm{C} / \mathrm{s}$ ), whereas our study involves a ferrite and pearlite initial microstructure and a heating rate at $5^{\circ} \mathrm{C} / \mathrm{s}$. In this sense, we believe that Kaluba et al. work is far from the present discussion. Moreover, as the referee mentioned, Kaluba et al. paper is very controversial, so we have decided not include this reference in the manuscript.

We have provided experimental Mf data in Table 2. These data are always below the two overaging temperatures selected. Although these data are above the room temperature there are some located austenite regions enriched in carbon with local values of Mf below the room temperature producing retained austenite in the final microstructure. Explanations in this sense have been included in results and discussion section.

\section{Overaging microstructures and continuous annealing.}

Figure 6: We have changed Figure 6 and explanations have been introduced along the text regarding the ferrite volume fraction presents in the microstructure following Referee's instructions.

Page 5: Third paragraph has been modified for better understanding as Referee suggests.

Last paragraph: Because the experimental Mf values for both microstructures are near $150^{\circ} \mathrm{C}$ we know that martensite transformation will not be completed at $200^{\circ} \mathrm{C}$ and $180^{\circ} \mathrm{C}$, so in both cases there will be tempered martensite and MA constituents in the final microstructure. The dilatometric curve gives an overall value of $\mathrm{Mf}$, so it only considers the total austenite volume fraction that transforms to martensite. This dilatometric curve does not take into account the fact that in the same sample different austenite regions exist and depending on their carbon content they will have different local values of Mf, so some of them will transform to martensite during the first cooling and others will transform after quenching from overaging. Therefore, we think that a typical dilatometric curve would not explain the amount of austenite that transforms into martensite before the overaging treatment. We are working in that direction. In the last paragraph our intention was to experimentally confirm that a decrease in the overaging temperature increases the final tempered martensite volume fraction because in this case more islands of austenite are able to transform to martensite (there are $20^{\circ} \mathrm{C}$ of difference between 200 and $180^{\circ} \mathrm{C}$ ) during the cooling from the partial austenitisation.

TYPOS

All typos were changed according to Referee's suggestions. 
If you need any further information, please do not hesitate contact me. Thank you very much for your kind cooperation.

Awaiting your early news on the matter, I remain, Sincerely yours,

Dr. Francisca G. Caballero

E-mail Address: fgc@cenim.csic.es 